\title{
HUBUNGAN ANTARA GAYA BELAJAR DAN MOTIVASI BELAJAR DENGAN PRESTASI BELAJAR MAHASISWA PROGRAM STUDI PENDIDIKAN TEKNIK ELEKTRO UNIVERSITAS NEGERI JAKARTA
}

\author{
${ }^{1}$ Nurul Citra Pratiwi, ${ }^{2}$ Soeprijanto, ${ }^{3}$ Faried Wadjdi. \\ 1,2,3 Pendidikan Teknik Elektro, Fakultas Teknik, Universitas Negeri Jakarta \\ 1,2,3 Email : nurulcitrapratiwi@gmail.com, soeprijanto@unj.ac.id, faried@unj.ac.id
}

\begin{abstract}
As purposes of this research are to know: 1) The closeness of the relationship between learning style with learning achievement; 2) The closeness of the relationship between learning motivation with learning achievement; 3) The closeness of the relationship between learning style and learning motivation with learning achievement of Electrical Engineering Education Students at Jakarta State University. In this research using a survey method with a quantitative approach. The population in this research are Electrical Engineering Education at Jakarta State University with an affordable population of Electrical Engineering Students at Jakarta State University in 2017 with a sample of 70 students. The analysis data techniques use descriptive statistical techniques, correlation hypothesis testing, simple regression tests, multiple regression tests that were previously performed prerequisite tests of analysis using the normality test and linearity test. The result showed that the result of the hypothesis test analysis with a significant level of 5\% showed that there was a positive and significant relationship between learning style with learning achievement test result $r_{\text {count }}=0,56>r_{\text {table }} 0,235$ with $t_{\text {count }}$ of $5,57 \%>t_{\text {table }} 1,995$ then the results of analysis of students learning styles produce dominant learning styles owned by students are the kinesthetic style by $38,571 \%$, the visual style by 28,571\%, the visual-kinesthetic styleby 22,857\%, the auditory and visual-auditory by 4,286\% and the least auditory-kinesthetic style by 1,429\%; then there is a positive and significant relationship between learning motivation with learning achievement test result $r_{\text {count }}=0,503>r_{\text {table }} 0,235$ with $t_{\text {count }}$ of 4,8>t table 1,995; and there is a positive and significant relationship between learning styles and learning motivation together with learning achievement $R_{\text {count }}=0,606>R_{\text {tabel }} 0,235$ with $F_{\text {count }} 19,44>F_{\text {tabel }} 3,31$.
\end{abstract}

Keywords: Learning Style, Learning Motivation, Learning Achievement.

\begin{abstract}
Abstrak
Penelitian ini bertujuan untuk mengetahui: 1) Keeratan hubungan antara gaya belajar dengan prestasi belajar; 2) Keeratan hubungan antara motivasi belajar dengan prestasi belajar; 3) Keeratan hubungan gaya belajar dan motivasi belajar secara bersama-sama dengan prestasi belajar mahasiswa Pendidikan Teknik Elektro Universitas Negeri Jakarta. Pada penelitian ini menggunakan metode survey dengan pendekatan kuantitatif. Populasi dalam penelitian adalah mahasiswa Pendidikan Teknik Elektro Universitas Negeri Jakarta dengan populasi terjangkau mahasiswa Pendidikan Teknik Elektro Universitas Negeri Jakarta angkatan tahun 2017 dengan sampel sebanyak 70 mahasiswa. Teknik analisis data yang digunakan teknik statistika deskriptif, uji hipotesis korelasi, uji regresi sederhana, uji regresi ganda yang sebelumnya dilakukan uji prasyarat analisis menggunakan uji normalitas dan uji linieritas. Hasil penelitian menunjukkan bahwa, hasil analisi uji hipotesis dengan taraf signifikan 5\% menunjukkan terdapat hubungan yang positif dan signifikan antara gaya belajar dengan prestasi belajar hasil pengujian $r_{\text {hitung }}=0,56>r_{\text {tabel }}=0,235$ dengan $t_{\text {hitung }}$ sebesar 5,57 $>t_{\text {tabel }}$ 1,995 kemudian hasil analisis gaya belajar mahasiswa menghasilkan gaya belajar dominan yang dimiliki mahasiswa yaitu gaya kinestetik sebesar 38,571\%, gaya visual sebesar $28,571 \%$, gaya visual-kinestetik sebesar $22,857 \%$, gaya auditorial dan visual-auditorial sebesar $4,286 \%$ dan yang paling sedikit gaya auditorial-kinestetik 1,429\%; hipotesis selanjutnya terdapat hubungan yang positif dan signifikan antara motivasi belajar dengan prestasi belajar hasil pengujian $r_{\text {hitung }}=0,503>r_{\text {tabel }}=0,235$ dengan $t_{\text {hitung }}$ sebesar $4,8>\mathrm{t}_{\text {tabel }}$ 1,995; dan terdapat hubungan yang positif dan signifikan antara gaya belajar dan motivasi belajar secara bersama-sama dengan prestasi belajar hasil pengujian $R_{\text {hitung }}=0,606>R_{\text {tabel }}=0,235$ dengan $F_{\text {hitung }} 1,44>F_{\text {tabel }} 19,44$.
\end{abstract}

Kata kunci: Gaya Belajar, Motivasi Belajar,Prestasi Belajar

\section{PENDAHULUAN}

Pendidikan merupakan suatu aspek yang sangat penting dalam menunjang pembangunan bangsa. Salah satu Subjek pembangunan dari pendidikan tersebut ialah manusia yang perlu dididik, dibina, serta dikembangkan potensipotensinya dengan tujuan tercapainya subjeksubjek pembangunan yang berkualitas. ${ }^{[1]}$ Salah satu sarana pendidikan ialah pendidikan tinggi, pendidikan tinggi adalah kelanjutan pendidikan menengah yang diselengarakan untuk menyiapkan peserta didik menjadi anggota masyarakat yang memiliki kemampuan akademik dan/atau professional yang dapat menerapkan, mengembangkan, menciptakan ilmu pengetahuan teknologi dan/atau kesenian (DepDikNas,2000: 2). Peserta didik dalam pendidikan tinggi dikenal sebagai mahasiswa. Suatu bidang pendidikan perlu adanya suatu hasil belajar yang disebut dengan prestasi belajar. ${ }^{[2]}$ Prestasi belajar mahasiswa menurut perguruan tinggi ialah berupa simbol dalam bentuk IPK (PerMenDikBud,2014: 13). 
${ }^{[3]}$ Setiap mahasiswa memiliki keunikan pribadi yang berbeda-beda tiap individunya seperti dalam tingkat kinerja, kecepatan belajar, gaya belajar serta motivasi belajar yang dimiliki (Slavin, 2011:126). ${ }^{[4]}$ Dunn Opal dalam (Sopiatin dan Sahrani, 2011: 4), menjelaskan bahwa dalam belajar, setiap individu memiliki kecenderungan kepada salah satu cara atau gaya tertentu. Kecenderungan seseorang ini disebut gaya belajar. ${ }^{[5]}$ Mengetahui gaya belajar mahasiswa sangat besar manfaatnya, diantaranya dapat menciptakan suasana belajar yang menyenangkan bagi mahasiswa, menimbulkan motivasi belajar, mengurangi konflik yang timbul sebagai akibat dari belajar (Wahyuddin, 2016: 106). Setelah melakukan observasi kepada mahasiswa Pendidikan Teknik Elektro bahwa terdapat perbedaan individual dalam belajar, dari cara menerima informasi ada mahasiswa dalam menangkap informasi sangat baik apabila dilakukan secara diskusi kelompok, atau terdapat mahasiswa yang dapat paham jika mereka langsung mengerjakannya atau terlibat secara langsung, namun masih terdapat beberapa mahasiswa yang hanya menerima pembelajarannya saja tanpa mengetahui bahwa dengan cara belajar seperti apa yang dapat membuatnya lebih mudah paham terhadap informasi yang diterimanya. Kebanyakan dari mereka hanya ikut teman-teman saja cara belajarnya jika ada teman yang berdiskusi mereka ikutan, jika mereka belajar sendiri kebanyakan dari mereka hanya membaca sekilas tanpa mengetahui konsep pembelajaran yang dapat mereka pahami. Mereka kurang memahami cara memanfaatkan gaya belajar yang seharusnya mereka gunakan guna mempermudah dalam memahami pelajaran. Serta terdapat beberapa mahasiswa yang dapat belajar jika situasi lingkungannya itu nyaman namun pada kenyataannya lingkungannya kurang membuat mereka nyaman dalam belajar. Permasalahan tersebut mengindikasikan bahwa mahasiswa yang mampu menangkap materi sesuai dengan gaya belajarnya tidak akan sulit dalam pemahaman suatu materi. Selain gaya belajar yang merupakan pendukung dalam proses pembelajaran dan hasil belajar, adapula motivasi belajar yang tidak kalah penting dalam pembangunan pendidikan. Lepas dari gaya belajar yang dimiliki setiap individu tersebut berbeda-beda. Bahwa pelajar atau mahasiswa merupakan makhluk sosial yang artinya bagaimana pun manusia tidak dapat terlepas dari individu yang lain. ${ }^{[6]}$ Mahasiswa sangat membutuhkan motivasi eksternal yang diberikan baik dari dosen, keluarga ataupun lingkungan pertemanan (Uno, 2007: 7). Adanya motivasi, mahasiswa akan terdorong semangatnya demi mendapatkan hasil belajar yang baik, dan untuk medapatkan hasil yang baik diperlukan proses dan motivasi yang baik pula. Sebab itulah para ahli psikologi pendidikan mulai memerhatikan mengenai stimulasi yang dinamakan motivasi. ${ }^{[7]}$ Motivasilah yang mendorong peserta didik untuk melakukan kegiatan pembelajaran atau dapat disebut pula bahwa motivasi berfungsi sebagai motor penggerak dari setiap kegiatan yang akan dikerjakan, dapat memberikan arah dan kegiatan yang harus dikerjakan serta dapat menyeleksi kegiatan yang harus dikerjakan sesuai dengan tujuannya (Majid, 2013: 309). Setelah melakukan obsevarsi kepada mahasiswa Pendidikan Teknik Elektro terdapat beberapa mahasiswa yang memiliki motivasi belajar yang rendah yang disebabkan oleh beberapa faktor seperti sebagian besar mahasiswa yang masuk program studi ini bukan inisiatif dari dirinya melainkan atas perintah orang tua atau asal memilih, serta lingkungan pertemanan yang kurang mendukung dalam belajar. Oleh karena itu mengakibatkan minat dalam belajarpun menurun yang mengakibatkan pada prestasi belajar yang diperoleh.

Prestasi belajar kurang optimal terjadi akibat dari pengaruh beberapa faktor salah satunya adalah pengaruh dari gaya belajar dan motivasi belajar. Prestasi belajar siswa di perguruan tinggi yang dinyatakan dalam IPK mahasiswa akan tercapai jika menggunakan gaya belajar sesuai dengan kepribadiannya serta adanya motivasi yang membangun demi tujuan tersebut begitu sebaliknya jika mahasiswa tidak menggunakan gaya belajar yang sesuai dengan kepribadiannya dan rendahnya motivasi belajar mahasiswa akan berakibat pada IPK yang kurang optimal. Prestasi belajar merupakan salah satu indiaktor keberhasilan studi mahasiswa. Prestasi belajar yang baik 
diharapkan mampu menggambarkan kualitas mahasiswa pula. Berdasarkan uraian masalah diatas, penulis akan melakukan penelitian tentang hubungan antara gaya belajar dan motivasi belajar dengan prestasi belajar mahasiswa Program Studi Pendidikan Teknik Elektro Universitas Negeri Jakarta.

\section{METODE PENELITIAN}

Metode penelitan yang digunakan adalah survey yang bersifat deskriptif korelasional dengan pendekatan kuantitatif. ${ }^{[8]}$ Sugiyono (2015:17) pendekatan kuantitatif, yaitu dengan pengumpulan data menggunakan instrumen penelitian, analisis data bersifat kuantitatif/statistik dengan tujuan untuk menguji hipotesis yang telah ditetapkan. ${ }^{[9]}$ Metode penelitian analisis korelasi dipilih karena akan mempelajari hubungan dua variabel atau lebih, yakni hubungan variasi dalam satu variabel dengan variabel lain (Arifin, 2011: 48). Penggunaan metode ini dimaksudkan untuk mengetahui hubungan gaya belajar dan motivasi belajar dengan prestasi belajar.

Dalam hal ini variabel gaya belajar $\left(\mathrm{X}_{1}\right)$ dan motivasi belajar $\left(\mathrm{X}_{2}\right)$ dengan variabel prestasi belajar (Y).

Populasi target pada penelitian ini adalah mahasiswa Pendidikan Teknik Elektro Universitas Negeri Jakarta. Sedangkan populasi terjangkau dalam penelitian ini adalah mahasiswa angkatan 2017 Pendidikan Teknik Elektro Universitas Negeri Jakarta, dengan jumlah mahasiswa sebanyak 73 mahasiswa. Pada penelitian ini pengambilan sampel menggunakan Simple Random Sampling, ${ }^{[10]}$ Sugiyono (2010: 93) dikatakan simple (sederhana) karena pengambilan anggota sampel dari populasi dilakukan secara acak tanpa memperhatikan strata yang ada dalam populasi tersebut.

Teknik pengumpulan data untuk variabel prestasi belajar berupa dokumentasi data IPK yang diperoleh dari admin Program Studi Pendidikan Teknik Elektro Universitas Negeri Jakarta sedangkan variabel gaya belajar dan motivasi belajar menggunakan angket. Instrumen penelitian diuji validitasnya menggunakan rumus product moment, Sedangakan untuk uji reliabilitas menggunakan teknik Alpha Cronbach. Teknik analisis data yang digunakan dalam peneitian ini menggunakan statistika deskriptif. Pengujian hipotesis menggunakan $\alpha=0,05$, namun sebelum melakukan uji hipotesis, terlebih dahulu dilakukan uji prasyarat analisis yaitu uji normalitas menggunakan chi-kuadrat dan uji linieritas. Lalu setelah melakukan uji prasyarat maka dilakukan uji hipotesis dengan analisis korelasi.

\section{HASIL DAN PEMBAHASAN Variabel Prestasi Belajar}

Berikut adalah distribusi frekuensi prestasi belajar yang dapat dilihat pada Tabel 1 .

Tabel 1. Distribusi Frekuensi Prestasi Belajar

\begin{tabular}{cccc}
\multicolumn{4}{c}{ Belajar } \\
\hline No. & $\begin{array}{c}\text { Interval } \\
\text { kelas }\end{array}$ & $\mathrm{f}$ & Persentase \\
\hline 1 & $66,75-70,14$ & 1 & $1,429 \%$ \\
2 & $70,15-73,54$ & 2 & $1,429 \%$ \\
3 & $73,55-76,94$ & 12 & $17,143 \%$ \\
4 & $76,95-80,34$ & 17 & $24,286 \%$ \\
5 & $80,35-83,74$ & 24 & $34,285 \%$ \\
6 & $83,75-87,14$ & 10 & $14,285 \%$ \\
7 & $87,15-90.54$ & 5 & $7,143 \%$ \\
\hline \multicolumn{2}{l}{ Jumlah } & 70 & $100 \%$ \\
\hline
\end{tabular}

\section{Variabel Gaya Belajar}

Berikut adalah distribusi frekuensi gaya belajar yang dapat dilihat pada Tabel 2.

Tabel 2. Distribusi Frekuensi Data Gaya Belajar Mahasiswa

\begin{tabular}{cccc}
\hline No. & $\begin{array}{c}\text { Interval } \\
\text { kelas }\end{array}$ & $\mathrm{f}$ & Persentase \\
\hline 1 & $2-17$ & 6 & $8,571 \%$ \\
2 & $18-33$ & 4 & $5,714 \%$ \\
3 & $34-49$ & 24 & $34,286 \%$ \\
4 & $50-65$ & 21 & $30,000 \%$ \\
5 & $66-81$ & 12 & $17,143 \%$ \\
6 & $82-97$ & 1 & $1,429 \%$ \\
7 & $97-113$ & 2 & $2,857 \%$ \\
\hline \multicolumn{2}{c}{ Jumlah } & 70 & $100 \%$ \\
\hline
\end{tabular}

\section{Profil Gaya Belajar}

Profil gaya belajar pada mahasiswa Pendidikan Teknik Elektro Universitas Negeri Jakarta dapat ditentukan dari hasil data angket 
penentu gaya belajar, Data angket yang diperoleh dari setiap responden akan dibuat rekapitulasi berdasarkan masing-masing gaya belajar.

${ }^{[11]}$ Berikut ini langkah-langkah dalam analisis data tersebut:

1. Terdapat beberapa pernyataan dalam instrumen angket yang akan diisi oleh responden. Terdapat tiga kelompok pernyataan yang mencermikan masingmasing gaya belajar yaitu kelompok gaya belajar "V" (Visual), kelompok gaya belajar "A" (Auditorial), kelompok gaya belajar "K" (Kinestetik). Setiap pernyataan memiliki jawaban pilihan "selalu" diberi skor 4 untuk pernyataan positif dan skor 1 untuk pernyataan negatif, "sering" diberi skor 3 untuk pernyataan positif dan skor 2 untuk pernyataan negatif, “jarang”diberi skor 2 untuk pernyataan positif dan skor 3 untuk pernyataan negatif ,"tidak pernah" diberi skor 1 untuk pernyataan positif dan skor 4 untuk pernyataan negatif

2. Dari masing-masing kelompok pernyataan gaya belajar, skor tersebut dijumlah sehingga pada tiap-tiap kelompok pernyataan akan menghasilkan nilai tertentu.

3. Penarikan kesimpulan penentu gaya belajar yang dimiliki masing-masing mahasiwa dengan cara membandingkan tiga nilai masing-masing kelompok pernyataan yang diisi oleh subjek tersebut, penarikan kesimpulan didasarkan pada:

a) Jika terdapat nilai tertinggi pada suatu kelompok pernyataan gaya belajar,maka disimpulkan subjek tersebut cenderung dominan pada gaya belajar tersebut;

b) Jika terdapat dua nilai tertinggi yang sama dari dua kelompok pernyataa gaya belajar, maka subjek tersebut tergolong pada "gabungan kedua gaya belajar" tersebut;

c) Jika terdapat dua nilai tertinggi dari dua kelompok pernyataan gaya belajar yang berselisih 1 poin, maka subjek tersebut tergolong pada "gabungan kedua gaya belajar" tersebut. d) Setelah itu, akan dibuat rekapitulasi berupa presentase penentu gaya belajar dari mahasiswa Pendidikan Teknik Elektro angkatan 2017. (Sari, 2014:5).

Selanjutnya, ${ }^{[12]}$ penentu gaya belajar mahasiswa yang diperoleh dari instrumen angket dihitung dengan menggunakan rumus:

\section{Persentase mahasiswa $=$}

Jumlah masiswa yang diperoleh

Jumlah total maksimum seluruh mahasiswa $x 100 \%$

(Taqwa, Astalini \& Darmaji, 2015: 222).

Data hasil analisis gaya belajar dapat dilihat pada Tabel 3.

Tabel 3. Presentase Gaya Belajar Mahasiswa

\begin{tabular}{ccc}
\hline \multicolumn{3}{c}{ Ringkasan Presentase Gaya Belajar } \\
\hline Visual & 20 & $28,571 \%$ \\
Auditorial & 3 & $4,286 \%$ \\
Kinestetik & 27 & $38,571 \%$ \\
Visual-Auditoial & 3 & $4,286 \%$ \\
Visual-Kinestetik & 16 & $22,857 \%$ \\
Auditorial-Kinestetik & 1 & $1,429 \%$ \\
\hline Jumlah & 70 & $100 \%$ \\
\hline
\end{tabular}

\section{Variabel Motivasi Belajar}

Berikut adalah distribusi frekuensi motivasi belajar yang dapat dilihat pada Tabel 4 .

Tabel 4. Distribusi Frekuensi Data Motivasi

\begin{tabular}{cccc}
\multicolumn{4}{c}{ Belajar } \\
\hline No. & Interval kelas & $\mathrm{f}$ & Persentase \\
\hline 1 & $90-94$ & 3 & $4,286 \%$ \\
2 & $95-99$ & 11 & $15,714 \%$ \\
3 & $100-104$ & 16 & $22,857 \%$ \\
4 & $105-109$ & 19 & $27,143 \%$ \\
5 & $110-114$ & 14 & $20,000 \%$ \\
6 & $115-119$ & 5 & $7,143 \%$ \\
7 & $120-124$ & 2 & $2,857 \%$ \\
\hline \multicolumn{2}{c}{ Jumlah } & 70 & $100 \%$ \\
\hline
\end{tabular}

\section{Uji Normalitas}

Berikut adalah perhitungan uji normalitas gaya belajar dan motivasi belajar dengan prestasi belajar yang dapat dilihat pada Tabel 5 . 
Tabel 5. Uji normalitas gaya belajar dan motivasi belajar dengan prestasi belajar

\begin{tabular}{lcccc}
\hline & $\mathbf{d k}$ & $\chi^{2}{ }_{\text {hitung }}$ & $\chi_{\text {tabel }}^{2}$ & Kesimpulan \\
\hline $\begin{array}{l}\text { Prestasi } \\
\text { Belajar }\end{array}$ & 6 & 3.822 & $\begin{array}{c}12.59 \\
2.5\end{array}$ & Normal \\
$\begin{array}{l}\text { Gaya } \\
\text { Belajar }\end{array}$ & 6 & 11.774 & $\begin{array}{c}12.59 \\
2\end{array}$ & Normal \\
$\begin{array}{l}\text { Motivasi } \\
\text { Belajar }\end{array}$ & 6 & 0,662 & $\begin{array}{c}12.59 \\
2\end{array}$ & Normal \\
& & & 2 & \\
\hline
\end{tabular}

Pada tabel 5 untuk variabel prestasi belajar $\chi_{\text {hitung }}^{2}=3,822$, sedangkan $\chi_{\text {tabel }}^{2}=12,592$, untuk $\alpha=0,05$ dan $\mathrm{dk}=6$. Karena $\chi_{\text {hitung }}^{2}<\chi_{\text {tabel }}^{2}$ maka dapat disimpulkan bahwa penyebaran data pada variabel prestasi belajar berdistribusi normal.

Dilanjutkan variable gaya belajar yang memiliki $\chi_{\text {hitung }}^{2}=11,774$, sedangkan $\chi_{\text {tabel }}^{2}=$ 12,592, untuk $\alpha=0,05 \mathrm{dan} \mathrm{dk}=6$.

Karena $\chi_{\text {hitung }}^{2}<\chi_{\text {tabel }}^{2}$ maka dapat disimpulkan bahwa penyebaran data pada variabel gaya belajar berdistribusi normal.

Selanjutnya variabel motivasi belajar $\chi^{2}$ hitung $=0,662$, sedangkan $\chi_{\text {tabel }}^{2}=12,592$, untuk $\alpha=$ 0,05 dan $\mathrm{dk}=6$. Karena $\chi_{\text {hitung }}^{2}<\chi_{\text {tabel }}^{2}$ maka dapat disimpulkan bahwa penyebaran data pada variabel prestasi belajar berdistribusi normal.

\section{Uji Linieritas}

Berikut adalah perhitungan uji Linieritas gaya belajar dengan prestasi belajar dan motivasi belajar dengan prestasi belajar dapat dilihat pada Tabel 6 .

Tabel 6. Uji Linieritas

\begin{tabular}{ccc}
\hline & $\begin{array}{c}\text { Gaya Belajar } \\
\text { dengan } \\
\text { Prestasi } \\
\text { Belajar }\end{array}$ & $\begin{array}{c}\text { Motivasi } \\
\text { Belajar dengan } \\
\text { Prestasi Belajar }\end{array}$ \\
\hline Nilai F table & 1,81 & 1,76 \\
Nilai F & \\
Keterangan & 0,79 & 1,03 \\
\hline
\end{tabular}

Berdasarkan hasil pengujian Linieritas pada variabel gaya belajar dengan prestasi belajar Dilihat dari kriteria pengujian yang digunakan, maka diperoleh hasil pengujian hipotesis tersebut menunjukkan $\mathrm{F}_{\text {hitung }}<\mathrm{F}_{\text {tabel }}$ maka $\mathrm{H}_{0}$ diterima yang berarti terdapat persamaan linier antara variabel gaya belajar dengan prestasi belajar. Sedangkan hasil pengujian linieritas pada variabel motivasi belajar dengan prestasi belajar dapat dilihat dari kriteria pengujian yang digunakan, maka diperoleh hasil pengujian hipotesis tersebut $\mathrm{F}_{\text {hitung }}<\mathrm{F}_{\text {tabel }}$ maka $\mathrm{H}_{0}$ diterima yang berarti terdapat persamaan linier antara variabel motivasi belajar dengan prestasi belajar.

\section{Uji Hipotesis \\ Korelasi $\mathrm{X}_{1}$ dengan $\mathrm{Y}$}

Berikut adalah Perhitungan uji hipotesis korelasi product moment gaya belajar dengan prestasi belajar dapat dilihat pada Tabel 7 .

Tabel 7. Uji Korelasi Product Moment

\begin{tabular}{ccccc}
\hline $\mathbf{n}$ & $\boldsymbol{\alpha}$ & rhitung & rtabel & Ket \\
\hline $\mathbf{7 0}$ & 0,05 & 0,56 & 0,235 & $\mathrm{H}_{\mathrm{a}}$ diterima
\end{tabular}

\section{Korelasi $\mathrm{X}_{2}$ dengan $\mathrm{Y}$}

Berikut adalah Perhitungan uji hipotesis korelasi product moment motivasi belajar dengan prestasi belajar dapat dilihat pada Tabel 8.

Tabel 8. Uji Korelasi Product Moment

\begin{tabular}{ccccc}
\hline $\mathbf{n}$ & $\boldsymbol{\alpha}$ & rhitung & rtabel & Ket \\
\hline $\mathbf{7 0}$ & 0,05 & 0,503 & 0,235 & $\mathrm{H}_{\mathrm{a}}$ diterima
\end{tabular}

\section{Korelasi $\mathrm{X}_{1}$ dan $\mathrm{X}_{2}$ dengan $\mathrm{Y}$}

Berikut adalah Perhitungan uji hipotesis korelasi ganda gaya belajar dan motivasi belajar secara bersama-sama dengan prestasi belajar dapat dilihat pada Tabel 9.

Tabel 9. Uji Korelasi Ganda

\begin{tabular}{ccccc}
\hline $\mathbf{n}$ & $\boldsymbol{\alpha}$ & $\mathbf{R}_{\text {hitung }}$ & $\mathbf{R}_{\text {tabel }}$ & Ket \\
\hline $\mathbf{7 0}$ & 0,05 & 0,606 & 0,235 & $\begin{array}{c}\mathrm{H}_{\mathrm{a}} \\
\text { diterima }\end{array}$ \\
\hline
\end{tabular}

\section{KESIMPULAN DAN SARAN \\ Kesimpulan}

Berdasarkan pembahasan yang telah diuraikan sebelumnya, maka diperoleh kesimpulan sebagai berikut:

1. Berdasarkan pengujian hipotesis pertama, diketahui $r_{x_{1} y}=0,56$ dengan derajat kebebasan 68 dan taraf signifikan $5 \%$ dan 
rtabel sebesar 0,235. Dilihat dari kriteria pengujian yang digunakan, terlihat hasil pengujian tersebut menunjukkan $r_{\text {hitung }}>r_{\text {tabel }}$ maka $\mathrm{H}_{0}$ ditolak dan $\mathrm{H}_{\mathrm{a}}$ diterima yang berarti terdapat hubungan yang positif antara variabel gaya belajar dengan prestasi belajar mahasiswa. Untuk hasil signifikansinya terbukti signifikan karena didapatkan nilai $\mathrm{t}_{\text {tabel }}$ sebesar 1,995 dan $\mathrm{t}_{\text {hitung }}$ sebesar 5,569, yang berarti $t_{\text {hitung }}>t_{\text {tabel }}$, dengan nilai koefesiensi determinan sebesar 31,3\%, kemudian berdasarkan hasil data presentase gaya belajar didapatkan bahwa gaya belajar yang dominan pada mahasiswa Pendidikan Teknik Elektro adalah gaya belajar kinestetik sebesar 38,571\% dengan bantuan visual dan auditorial. Dengan ini setiap mahasiswa tidak hanya mendominasi satu gaya belajar saja tetapi dengan beradaptasi dengan gaya belajar lain.

2. Berdasarkan pengujian hipotesis kedua, diketahui $r_{x_{2} y}=0,503$ dengan derajat kebebasan 68 dan taraf signifikan $5 \%$ dan rtabel sebesar 0,235. Dilihat dari kriteria pengujian yang digunakan, terlihat hasil pengujian tersebut menunjukkan $r_{\text {hitung }}>r_{\text {tabel }}$ maka $\mathrm{H}_{0}$ ditolak dan $\mathrm{H}_{\mathrm{a}}$ diterima yang berarti terdapat hubungan yang positif antara variabel motivasi belajar dengan prestasi belajar mahasiswa. Untuk hasil signifikansinya terbukti signifikan karena didapatkan nilai $t_{\text {tabel }}$ sebesar 1,995 dan thitung sebesar 4,8 , yang berarti $t_{\text {hitung }}>\mathrm{t}_{\text {tabel }}$, dengan nilai koefesiensi determinan sebesar $25,3 \%$.

3. Berdasarkan pengujian hipotesis ketiga, diketahui $R_{x_{1} x_{2} y}=0,606$ dengan derajat kebebasan 68 dan taraf signifikan 5\% dan rtabel sebesar 0,235. Dilihat dari kriteria pengujian yang digunakan, terlihat hasil pengujian tersebut menunjukkan $\mathrm{R}_{\text {hitung }}>$ $\mathrm{R}_{\text {tabel }}$ maka $\mathrm{H}_{0}$ ditolak dan $\mathrm{H}_{\mathrm{a}}$ diterima yang berarti terdapat hubungan yang positif antara variabel gaya belajar dan motivasi belajar secara bersama-sama dengan prestasi belajar mahasiswa. Untuk hasil signifikansinya terbukti signifikan karen didapatkan nilai $F_{\text {tabel }}$ sebesar 3,31 dan $F_{\text {hitung }}$ sebesar 19,44, yang berarti $F_{\text {hitung }}>F_{\text {tabel}}$, dengan nilai koefesiensi determinan sebesar $37 \%$.

\section{Saran}

Berdasarkan hasil penelitian ini, penulis mempunyai saran antara lain:

1. Diharapkan untuk mahasiswa mengetahui gaya belajar yang sesuai dengan dirinya.

2. Setelah mengetahui kecenderungan gaya belajarnya, masing-masing mahasiswa diharapkan mampu memaksimalkan cara belajar yang tepat serta memanfaatkan gaya belajarnya dalam menyerap dan memahami sebuah informasi, agar mendapat prestasi belajar yang maksimal.

3. Mahasiswa harus bisa menumbuhkan motivasi dalam dirinya seperti sadar akan cita-cita dimasa depan agar termotivasi dalam belajar dan mendapatkan prestasi belajar yang maksimal.

4. Mahasiswa setidaknya dapat memilih lingkung belajar yang memiliki motivasi yang tinggi agar dapat membawa pengaruh yang baik bagi dirinya dan prestasi yang dicapai.

5. Saran untuk penelitian selanjutnya, sebaiknya penelitian yang lebih lanjut berkaitan dengan gaya belajar dapat menggunakan metode observasi dalam mengamati setiap gaya belajar yang dimiliki mahasiswa, sebab pada penelitian ini hanya menggunakan kuesioner sehingga dalam pengisian kuesioner tersebut belum tentu sesuai dengan keadaan yang sebenarnya. Dan pengetahuan untuk melakukan penelitian sejenis diharapkan mampu menemukan variabel lain yang lebih luas dan variatif sehingga dapat menambah hasil-hasil penelitian.

\section{DAFTAR PUSTAKA}

[1]DepDikNas. 2000. KepMenDikNas RI No 232/U/2000.Tentang Pedoman Penyusunan Kurikulum Pendidikan Tinggi dan Penilian Hasil Belajar Mahasiswa. Jakarta.

[2]Peraturan Menteri Pendidikan dan Kebudayaan Republik Indonesia. No.49 tahun 2014. Tentang Standar Nasional Pendidikan Tinggi. Jakarta.

[3]Slavin, Roberto E. (2011). Psikologi Pendidikan : Teori dan Praktik. Penerjemah: Marianto Samosir. Jakarta: PT Indeks. 
[4]Sopiatin, Popi \& Sahrani, Sohari. 2011. Psikologi Belajar dan Prespektif Islam. Bogor: Ghalia Indonesia.

[5]Wahyuddin, Wawan. 2016. "Gaya Belajar Mahasiswa (Studi Lapangan di Program Pascasarjana IAIN "SMH" Banten)". AlQalam vol.33 no.1:105-120.

[6]Uno, Hamzah B. 2007. Teori Motivasi dan Pengukurannya Analisis di Bidang Pendidikan. Jakarta: Bumi Aksara

[7]Majid, Abdul. 2013. Strategi Pembelajaran. Bandung:PT Remaja Rosdakarya.

[8]Sugiyono. 2015. Metode Penelitian Kuantitatif, Kualitatif dan R\&D. Bandung: Alfabeta.

[9]Arifin, Zainal. 2011. Penelitian Pendidikan Metode dan Paradigma Baru. Bandung: PT. Remaja Rosdakarya.

[10]Sugiyono. 2010. Metode Penelitian Administrasi Dilengkapi dengan Metode $R \& D$. Bandung: Alfabeta.

[11]Sari, Ariesta Kartika. 2014." Analisis Karakteristik Gaya Belajar VAK (Visual, Auditorial, Kinestetik) Mahasiswa Pendidikan Informatika Angkatan 2014". Jurnal Ilmiah Edutic vol.I no.1: 1-11

[12]Taqwa,. Astalini,. Darmaji,. 2015. “ Hubungan Gaya Belajar Visual, Auditorial, dan Kinestetik dengan Hasil Belajar Siswa Pada Materi Dinamika Rotasi dan Kesetimbangan Benda Tegar Kelas XI IPA SMAN Se-Kota Jambi”. Prosiding Seminar Nasional Sains dan Pendidikan Sains 5: 220-227. 